\title{
Científicos Sociales Latinoamericanos en Estados Unidos: Cooperación Académica, Movilidad Internacional y Trayectorias Interamericanas alrededor de la Fundación Ford*
}

\author{
Juan Jesús Morales \\ Universidad Bernardo O'Higgins, Santiago, Chile. E-mail: jmoralesma@ucsh.cl
}

\section{INTRODUCCIÓN}

lobjetivo principal de este artículo es examinar las redes de coope-

¿ ración académica y los canales de movilidad internacional establecidos por la Fundación Ford en América Latina, los cuales actuaron como plataformas de promoción de científicos sociales de la región en Estados Unidos y les permitieron además ser considerados como prestigiosos por parte de sus pares norteamericanos y reconocidos entonces con credenciales de responsabilidad institucional en aquel país. Más en concreto nuestro interés está puesto en comprender la vinculación de autores como Fernando H. Cardoso o Guillermo O`Donnell con algunos "diplomáticos" de esta institución filantrópica para desarrollar actividades institucionales e intelectuales en Estados Unidos. Por esto último, y a modo de hipótesis de investigación, queremos responder a la pregunta de cómo se realizaron estas interacciones y vínculos interamericanos a mediados de los años 1970 del pasado siglo XX.

Los conceptos de "diplomacia académica" y de "diplomáticos académicos" nos ayudarán a entender las acciones y las prácticas de la Fundación Ford y de sus representantes en América Latina en su papel de autoridad a la hora de decidir qué instituciones y qué científicos

* Este texto se enmarca en el proyecto Fondecyt de Iniciación a la Investigación 2015 № 11150026: “Una alianza para la democracia: la Fundación Ford y el circuito latinoamericano de centros académicos independientes en tiempos de autoritarismo (1969-1990). Un análisis de los casos de CEDES, CEBRAP y CIEPLAN".

DADOS - Revista de Ciências Sociais, Rio de Janeiro, vol. 60, no22, 2017, pp. 473 a 504. 
Juan Jesús Morales

debían beneficiar con sus donaciones. Por tal motivo, entendemos por "diplomacia académica" el conjunto de actividades desarrolladas por esta institución filantrópica norteamericana para articular sus relaciones con instituciones académicas regionales y evaluar sus apoyos económicos destinados a la promoción de la actividad científica e investigadora. Mientras que con "diplomáticos académicos" nos referimos a aquellos agentes enviados para promover y evaluar estas acciones de cooperación académica internacional (Abarzúa, 2012; González-Chiaramonte, 2008; Rizzo, 2012). Unos agentes que también suelen ejercer, en ocasiones, como mediadores entre el mundo de la política y el mundo de la academia (Puryear, 1994; Calandra, 2012). Esas dos nociones son complementarias analíticamente al concepto de "red" cuando observemos el método de conducción de la Fundación Ford y de sus diplomáticos a la hora de establecer relaciones colaborativas, intelectuales y personales con científicos sociales latinoamericanos (Devés, 2007). Específicamente nos detendremos en cómo estas acciones y nexos establecidos permitieron generar espacios de autonomía académica y canales de comunicación internacional durante el contexto de autoritarismo con la creación de varios centros académicos independientes de Argentina, Brasil y Chile.

Respecto a la fundamentación metodológica, estudiaremos la trayectoria de algunos diplomáticos de la Fundación Ford con dilatada experiencia en la región. Nos ocuparemos de sus capacidades, sus experticias y sus prácticas mediadoras en el establecimiento de redes académicas y de colaboración que también tendrían derivaciones y alcances en Estados Unidos con la formación, justamente, de instituciones dedicadas al estudio de América Latina. Más en concreto, nos detendremos en la biografía de Abraham F. Lowenthal, quien junto a otros agentes, caso de Albert O. Hirschman o Kalman Silvert, más científicos sociales de la región, como los ya señalados Cardoso y O’Donnell, dieron forma al Programa Latinoamericano del Woodrow Wilson Center. Un seguimiento temporal y espacial a la movilidad académica internacional de estos autores, junto con sus nexos intelectuales y personales, nos permitirá la obtención del objetivo principal propuesto y la demostración de la hipótesis de trabajo. Pues el análisis documental de toda esta trama es el que nos permitirá observar cómo estos autores latinoamericanos - gracias a su participación en los canales de financiación, entrenamiento y reclutamiento de la Fundación Ford - fueron capaces de pensar y concebir instituciones académicas de prestigio en Estados Unidos ${ }^{1}$. 
Consideramos que la particularidad de este trabajo se encuentra en superar ciertas visiones parciales y redundantes sobre el estudio de las fundaciones privadas del centro académico mundial, pues, como así sucede con la Fundación Ford, habitualmente suelen ser vistas desde la periferia como agentes de dominación política y de reproducción de la dependencia académica (Berman, 1983). Al igual que son dibujadas como plataformas replicantes en el Sur de las luchas por el poder en el Norte, fundamentalmente de los debates académicos, culturales y políticos internos norteamericanos (Dezalay y Garth, 2002). Sin embargo, en las páginas que siguen queremos centrarnos en las historias intelectuales cruzadas y en las vías de comunicación de ida y vuelta abiertas entre el Norte y el Sur americanos, además de señalar el importante papel de ciertos agentes e intermediarios a la hora de establecer estos vínculos e interrelaciones interamericanas. Para ello seguiremos un enfoque basado en la "historia intelectual trasnacional" que nos ayudará a especificar la participación de igual a igual de científicos sociales latinoamericanos en estas redes de consagración, de generación de conocimiento y de intercambios intelectuales proporcionadas por la Fundación Ford (Adelman y Fajardo, 2016:3).

También, como antecedentes empíricos y teóricos, nos apoyamos en los trabajos alrededor de la "dependencia académica" dirigidos por Fernanda Beigel $(2010 ; 2013)$, los cuales se refieren a la estructura desigual de producción y circulación de conocimiento que existe en el sistema científico internacional, y que ha sido una preocupación recurrente en las comunidades intelectuales periféricas. Muy importante, y siguiendo ese enfoque, descuella el reciente libro de Fernando Quesada (2015:8) sobre la Fundación Ford y el convenio de colaboración establecido en los años 1960 entre la Universidad de Chile y la Universidad de California, al señalar las particulares, cambiantes y complejas formas de dominación que conllevan "las interrelaciones académicas y científicas entre los centros y las periferias" articuladas por las instituciones filantrópicas estadounidenses. Otro destacado antecedente historiográfico es el libro de Mark. T. Berger (1995) sobre el repaso de semblanzas biográficas, la descripción de instituciones, organizaciones y publicaciones que desarrollaron y trazaron la formación de los estudios latinoamericanos en Estados Unidos. Todas estas referencias permiten, en fin, precisar la posición teórica y el recorte analítico que presentamos en este texto, centrado, por tanto, en estudiar las repercusiones en ese país de los contactos personales y las interacciones intelectuales tejidas en América Latina alrededor de

DADOS - Revista de Ciências Sociais, Rio de Janeiro, vol. 60, nº 2, 2017 
las redes de la Fundación Ford por parte de una generación concreta de científicos sociales latinoamericanos.

\section{CAMINOS DE IDA Y VUELTA ENTRE LAS AMÉRICAS: LA FUNDACIÓN FORD COMO UNA INSTITUCIÓN DE "DIPLOMACIA ACADÉMICA"}

Para una adecuada formulación de la propuesta, es necesario exponer un breve marco de antecedentes que atienda la historia de la Fundación Ford y su papel en la creación de los Latin American Studies en Estados Unidos y en la consolidación de las ciencias sociales en América Latina en un tiempo histórico marcado por las coordenadas de la Guerra Fría. Para empezar, recordemos que esta institución filantrópica fue creada en 1936 en Detroit como una organización independiente, privada, no lucrativa y no gubernamental, dedicada a financiar programas de cooperación internacional que promuevan el desarrollo, la democracia y la reducción de la pobreza (Arnove, 1980; Fundación Ford, 2003; Quesada, 2010).

El interés por conocer lo que sucedía en otras partes del mundo y de intervenir en esas realidades, llevó a esta institución filantrópica, entre otras acciones, a fomentar a institucionalización de los estudios latinoamericanos en Estados Unidos con la creación en 1942 del Joint Committee on Latin American Studies del Social Science Research Council (Sibley, 2001). Con este comité se quería atender la demanda de un conocimiento experto sobre América Latina, perfilando el objeto de estudio disciplinar y promoviendo la formación y la profesionalización de cuadros académicos y docentes en las universidades norteamericanas ${ }^{2}$.

En 1962 se inició el programa de becas del Joint Committee on Latin American Studies gracias también al apoyo financiero de la Fundación Ford. Este programa se prolongó hasta los años 1990 y no solamente se dedicó a becar y financiar viajes de formación, de investigación y de perfeccionamiento en América Latina a "junior scholars" norteamericanos, sino que también incluyó a beneficiarios de la región para que realizasen pasantías en Estados Unidos (Worcester, 2001:63 y 120-121). De esta forma, el Joint Committee on Latin American Studies actuó como un destacado punto de intersección y encuentro entre la comunidad científica norteamericana y entre los científicos sociales latinoamericanos a partir de estos programas de becas e intercambios. Y justamente uno de esos puentes más sólidos entre ambas academias fue la Fundación Ford en su función de establecer vasos comunicantes entre 
universidades y científicos sociales de las dos Américas. Pues, en efecto, su presencia ya había sido clave en América Latina para el desarrollo de las ciencias sociales (Morales, 2016a).

Recordemos aquí que el inicio del Programa para Latinoamérica de esta institución filantrópica había comenzado en 1959 al calor de la Revolución cubana y con becas destinadas a Argentina, Brasil, Chile, Puerto Rico y a la antigua Federación de las Indias Occidentales (Calandra, 2011:11; Calandra, 2012:134; Ford Foundation, 1960:89). No por casualidad la Fundación Ford se sumó, a través de estas donaciones, como un instrumento diplomático más a toda la política de asistencia económica, técnica y científica que Estados Unidos brindó para la región con la Alianza para el Progreso de John F. Kennedy como respuesta a aquel suceso histórico (Calandra, 2015; Gabay, Morales y Navarro, 2013)3. De hecho, ayudó con sus recursos económicos al avance y a la profesionalización de la investigación social como a la consolidación de su comunidad académica, apoyando a instituciones públicas y universitarias latinoamericanas justo en un tiempo que coincidió con la edad de oro de las ciencias sociales regionales.

Efectivamente, el proceso de modernización en América Latina posterior a la Segunda Guerra Mundial ayudó a profesionalizar el campo de las ciencias sociales. La región recibió abundantes recursos humanos y materiales externos destinados al desarrollo de las disciplinas científicas y al desarrollo universitario (Beigel, 2010). Recordemos, en concreto, la presencia en la región de organismos internacionales, como la CEPAL, la FLACSO, el ILPES o el PNUD, que desde los años 1950 venían ejerciendo un importante rol en la formación de científicos sociales, en el suministro de especialistas y en la producción de conocimientos. Pero, a su vez, en este proceso de modernización y profesionalización de las ciencias sociales participaron otros actores, como las fundaciones privadas extranjeras.

De forma específica, el Programa para Latinoamérica de la Fundación Ford apoyó con sus donaciones la creación en la región de instituciones académicas y universitarias, estableció programas de becas y de cooperación académica internacional, sobre todo con Estados Unidos, e impulsó múltiples investigaciones y estudios sobre aspectos sociales, económicos y políticos del desarrollo latinoamericano (Morales, 2016b; Quesada, 2015) ${ }^{4}$. A la vez que concedía recursos económicos, esta institución filantrópica supervisaba en terreno los proyectos fi-

DADOS - Revista de Ciências Sociais, Rio de Janeiro, vol. 60, nº 2, 2017 
nanciados y se encargaba también de cuidar las relaciones personales y profesionales con los profesores y con las instituciones académicas beneficiadas. Además, a través de las donacionaes y siguiendo esta peculiar forma de trabajar, se insertaba y participaba, de hecho, en otras redes latinoamericanas de ciencias sociales, como las organizadas por la CEPAL o la FLACSO.

Para poder supervisar y evaluar el destino de las donaciones como al mismo tiempo articular redes de cooperación académica, la Fundación Ford decidió establecer en 1960 una primera oficina en Río de Janeiro. En 1962 abriría sendas oficinas en Buenos Aires y en Bogotá. Al año siguiente inauguraría una oficina en Santiago de Chile, la cual desde 1966 operó como sede regional de la institución. Luego en 1965 abriría otra oficina en Lima (Fundación Ford, 2003:17 y 95). A partir de estas oficinas y a través de sus agentes, el Programa para Latinoamérica consiguió, como gran logro de esos años, animar el circuito regional e interamericano de intercambio y circulación de conocimientos y de personas en un contexto políticamente complicado. Pues, en ese sentido, debemos señalar el recelo que hubo en América Latina hacia las fundaciones norteamericanas, coincidente además con la sensación de frustración sobre el alcance efectivo de las políticas de desarrollo y de cooperación multilateral en el continente impulsadas por la Alianza para el Progreso.

A ello se sumarían varios e importantes hechos, como la violenta interrupción de la experiencia reformista del gobierno brasileño de João Goulart, que fue derrocado en 1964, o la invasión norteamericana de la República Dominicana en 1965. Justo ese mismo año saldría a la luz un programa de investigación que generó un verdadero escándalo en la academia, en la política y en la opinión pública chilenas, conocido como Proyecto Camelot, que profundizó el descrédito en la región hacia la política externa de Estados Unidos (Navarro y Quesada, 2010) ${ }^{5}$. En 1966 se produjo el golpe de Estado del General Onganía en Argentina. Después vendría el giro realista de la política exterior norteamericana de Richard Nixon y seguirían más intervenciones militares, consumándose esta época de crisis y de oscuridad para América Latina con los golpes de Estado en el Cono Sur de los años 1970.

Todos los sucesos descritos generaron una imagen de desconfianza y de rechazo hacia las fundaciones norteamericanas, hacia sus representantes y sus donaciones. La Fundación Ford, en particular, quiso supe- 
rar este prejuicio desde el enfoque que había seguido su diplomacia académica en América Latina a la hora de apoyar, sostener y preservar la autonomía y la libertad de las ciencias sociales. De hecho sería la hoja de ruta que siguió ante las restricciones impuestas por las dictaduras militares, no apoyando con sus donaciones a los gobiernos autoritarios y, protegiendo, en cambio, las trayectorias de científicos sociales valorados como "buenos demócratas" y poseedores de credenciales académicas e intelectuales.

\section{RETROCESO DEMOCRÁTICO EN AMÉRICA LATINA Y EL RESPALDO DE LA FUNDACIÓN FORD AL PENSAMIENTO INDEPENDIENTE}

El camino de ida y vuelta entre las dos Américas se constriñó a comienzo de los años 1970. Muchos científicos sociales de la región se vieron obligados a tomar el camino del exilio por las dictaduras militares, incluyendo también como uno de sus destinos los Estados Unidos, donde ayudarían, sin duda, a consolidar los Latin American Studies. A pesar de ese difícil, represivo y violento contexto, la estrategia de la Fundación Ford para las ciencias sociales latinoamericanas se sustentó en apoyar, sostener y preservar la autonomía y la libertad de su ejercicio $^{6}$. Decidió entonces financiar la creación de varios "centros académicos independientes" que permitieron a un buen número de científicos sociales evitar el camino del destierro y proseguir sus tareas intelectuales e investigadoras, como entablar contactos y colaboraciones entre ellos ${ }^{7}$. Para tal acción esta institución filantrópica se valió de los apoyos informales y mutuos entre sus agentes y los académicos favorecidos por sus donaciones (Bell, 1971). Pues la Fundación Ford fue una entidad que, en el caso de América Latina, invirtió en conceptos de talento, de formación, de intercambio y de redes con tal de entablar fluidas comunicaciones intelectuales y profesionales entre sus agentes y los científicos sociales locales.

Esta orientación se consolidó durante la presidencia de McGeorge Bundy (1966-1979), quien emprendió una política para la Fundación Ford enfocada en la generación y en el cuidado del "capital humano" (Quesada, 2015:57). Por su parte, Kalman Silvert, quien desde 1967 hasta su muerte en 1976 fue Advisor y Director del Programa Latinoamericano de la institución (Morse, 1977), apoyó y profundizó esta perspectiva de buscar un mayor impacto académico y social de las donaciones e inversiones realizadas. Ello también se debía a la amplia experiencia y conocimiento de la región que tenía este profesor ${ }^{8}$. Silvert,

DADOS - Revista de Ciências Sociais, Rio de Janeiro, vol. 60, nº 2, 2017 
en consecuencia, estableció en América Latina una importante agenda de contactos con el mundo académico y universitario que fue muy útil para esta institución filantrópica en aquellos complejos años de autoritarismo. Esos mismos lineamientos también serían seguidos por Albert O. Hirschman, Advisor entre 1976-1979 y luego en 1982, y otros importantes agentes e intermediarios de la red tejida en esos años por la Fundación Ford, como, entre otros, Peter Bell, William Carmichael, Nita Manitzas, Abraham F. Lowenthal o Jeffrey Puryear.

Por ejemplo, Peter Bell y William Carmichael tuvieron un papel muy significativo en la trayectoria de Fernando H. Cardoso, porque ellos fueron quienes gestionaron la beca de la Fundación Ford para apoyar la creación del Centro Brasileño de Análisis y Planeamiento (CEBRAP) en Sao Paulo en septiembre de $1969^{9}$. El sociólogo brasileño había sido expulsado y "desposeído obligatoriamente" de su cátedra de la Universidad de San Pablo en abril de ese año, decidiendo entonces, según sus palabras, "crear un centro de investigación independiente, privado" (Cardoso, 2009:32). Él ya había tenido contacto con las fundaciones norteamericanas durante sus años en el ILPES de Santiago de Chile y tenía familiaridad con este estilo de trabajo:

\footnotetext{
algunos profesores se quejaban de que no podían aceptar dinero del imperialismo, y las fundaciones todavía era tabú aquí, no para mí, porque en la CEPAL eso era normal, el financiamiento a través de fundaciones y conocíamos la forma de ser independiente de los gobiernos, como generalmente se trabaja en los Estados Unidos (Cardoso, 2009:32).
}

En efecto, la experiencia chilena de Cardoso fue decisiva en su trayectoria académica e intelectual. Escapando del golpe militar en Brasil de 1964, llegó en mayo de ese año a Santiago para incorporarse como subdirector de la División de Planificación Social del ILPES (Morales, $2012)^{10}$. En ese contexto lograría ser partícipe e incluso referente de esa época dorada de las ciencias sociales latinoamericanas a partir de la primera formulación de la teoría de la dependencia. Pero también, como vemos, en Chile estableció comunicación y diálogo con los agentes y las redes de la Fundación Ford que después le serían de gran ayuda y utilidad para fundar CEBRAP (Morales, 2016b). Este centro académico independiente nació entonces como una "entidad privada, sin fines de lucro, especializada en la investigación interdisciplinar y de asistencia técnica en el campo delas ciencias sociales" y aglutinando a "un grupo de importantes científicos sociales brasileños"11. De hecho, 
abrió el camino a seguir para el resto de centros financiados por la Fundación Ford en ese contexto de autoritarismo.

En línea similar, Kalman Silvert no dudó en avalar a Guillermo O’Donnell para que recibiese la financiación necesaria de la Fundación Ford para fundar el Centro de Estudios de Estado y Sociedad (CEDES) en Buenos Aires en julio de 1975 (Algañaraz y Morales, 2016:235). En esa labor de asistencia y de mediación también fueron importantes las gestiones de algunos funcionarios de esta institución filantrópica, como David E. Bell, Abraham Lowenthal y de Nitas Maniztas ${ }^{12}$. Al igual que Cardoso, O’Donnell tenía desenvoltura con la academia y las fundaciones norteamericanas. En 1968 viajó a la Universidad de Yale, obteniendo en 1971 un Magíster en Ciencia Política (O’Donnell, 2007:275). A su vuelta a Argentina se incorporaría al Centro de Investigación en Administración Pública (CIAP), constituido en 1968 como centro independiente del Instituto Torcuato Di Tella y también financiado por la Fundación Ford ${ }^{13}$. No obstante, mantendría sus contactos en Estados Unidos, siendo en esos años profesor visitante en la Universidad de California y en la Universidad de Michigan en Ann Arbor. También era miembro del Joint Committee on Latin American Studies del SSRC (O`Donnell, 2007:279) ${ }^{14}$.

Los cometidos de Peter Bell y Jeffrey Puryear fueron claves, por otra parte, para la creación en 1976 y el posterior sostenimiento de la Corporación de Investigaciones Económicas para Latinoamérica (CIEPLAN), dirigida por Alejandro Foxley en Santiago de Chile ${ }^{15}$. Foxley contaba igualmente con experiencia en las redes de cooperación y de intercambio académico de las fundaciones norteamericanas en la región. Precisamente viajó becado por la Fundación Fulbright a la Universidad de Wisconsin, donde se doctoró en economía en $1966^{16}$. Después formaría junto a otros economistas chilenos el Centro de Estudios y Planificación Nacional (CEPLAN), institución creada en 1970 en la Facultad de Economía de la Universidad Católica y también financiada por la Fundación Ford. Siendo intervenida duramente esta casa de estudios superiores durante la dictadura militar y el Centro expulsado, tuvo que reorganizarse desde el lado privado (Fundación Ford, 2003:47; Meller y Walker, 2007).

Se observa, en consecuencia, cómo el apoyo, las donaciones y las redes de la Fundación Ford actuaron para estos centros académicos independientes como un paraguas ante las amenazas y las presiones de las dictaduras militares. Además, en esas tareas resultaron fundamentales

DADOS - Revista de Ciências Sociais, Rio de Janeiro, vol. 60, nº 2, 2017 
varios soportes personales e intelectuales, como los ofrecidos por Albert $\mathrm{O}$. Hirschman en su función de tejedor de redes institucionales, pues él se encargó de vincular y fortalecer la trama de CEBRAP, CEDES y CIEPLAN a partir de la formación de comités internacionales (Adelman, 2013: 576) ${ }^{17}$. Esta medida sirvió como una suerte de escudo y de resistencia. No por casualidad él fue miembro de los comités de estos centros académicos en los que también se entrelazaban los nombres de Cardoso, Foxley y O’Donnell. El fin era proteger a este grupo de jóvenes científicos sociales latinoamericanos y así evitar el exilio de éstos, asegurándoles un marco institucional y un ambiente de autonomía académica en cada escenario nacional.

Pero además estos centros asumieron una clara estrategia de colaboración académica y de internacionalización estableciendo una especie de "alianza" entre ellos a partir un "modelo cooperativo de proyectos" que les otorgaba tanto protección frente a las dictaduras militares como "visibilidad académica y reconocimiento profesional" en el exterior (Brunner y Barrios, 1987:132) ${ }^{18}$. A pesar de las dificultades las interacciones intelectuales y los contactos profesionales fueron habituales, habiendo una permanente movilidad académica entre Argentina, Brasil y Chile a partir de jornadas y seminarios que sirvieron para compartir conocimientos científicos y experiencias políticas vividas en cada país. A la vez se establecieron estrategias de circulación internacional de los investigadores y de sus trabajos, ya fuese por medio de conferencias y de estancias en universidades extranjeras como a través de publicaciones en revistas especializadas, preferentemente norteamericanas (Morales, 2016a).

Al mismo tiempo las redes y los canales interamericanos de la Fundación Ford y de sus agentes fueron vitales para la difusión de las actividades y de las investigaciones de este circuito de centros latinoamericanos, algunas veces escasamente conocidas en el interior de sus países. En el caso que nos ocupa, fue Hirschman quien actuó como un importante garante en Estados Unidos de esta nueva generación de científicos sociales de la región, invitándoles en esos años a pasantías académicas para que trabajaran junto a él en el Instituto de Estudios Avanzados de la Universidad de Princeton y avalándoles en becas y proyectos del Joint Committee on Latin American Studies del SSRC (O’Donnell, 2007: 279; Adelman, 2013: 467-477; Adelman y Fajardo, 2016: 9 y 10 ${ }^{19}$. De hecho, tuvo un cercano y especial trato personal e intelectual con Cardoso, Foxley y O`Donnell por aconsejar, apoyar y visi- 
tar sus centros académicos durante los años oscuros de las dictaduras militares en Argentina, Brasil y Chile (Foxley, 2013; Foxley, Mc Pherson y O'Donnell, 1989:10). Este ascendente de Hirschman sobre estos tres latinoamericanos sería clave cuando él, junto con Abraham F. Lowenthal, acometieran el diseño del primer Consejo Académico del Programa Latinoamericano del Wilson Center.

\section{TRAYECTORIAS Y ENTRECRUZAMIENTOS INTERAMERICANOS}

Abraham F. Lowenthal y Albert O. Hirschman se habían conocido en Perú en los años 1960 por medio de la Fundación Ford. Volverían a coincidir después en varios e importantes acontecimientos. Para entender las repercusiones intelectuales y asociativas de esos cruces, es conveniente detenernos ahora en la trayectoria académica y laboral del primero, ligada en diversos momentos a esa institución filantrópica. Un breve énfasis en esta biografía es la que nos va a permitir observar cómo este autor estadounidense fue adquiriendo competencias, capital social y profesional a la vez que fue consiguiendo legitimidad y credibilidad para mancomunar esfuerzos y encontrar socios académicos y soportes financieros a la hora de crear espacios y dispositivos institucionales como fue el Programa Latinoamericano del Wilson Center. Particularmente, lo que nos interesa con esta trayectoria es comprender el funcionamiento de las redes académicas interamericanas y de las élites intelectuales en la consecución de objetivos institucionales.

Al comienzo de su formación académica Lowenthal no mostró ningún interés específico en América Latina. Él había iniciado sus estudios de Derecho en la Kennedy School de la Universidad de Harvard en 1961 y después de un año se pasó a estudiar la Licenciatura de Administración Pública ${ }^{20}$. La flexibilidad y amplitud del programa académico le permitió asistir a varios seminarios de ciencias sociales. En octubre de 1962 y bajo el clima de la crisis de los misiles entre Cuba, Estados Unidos y la Unión Soviética, decidió tomar sendos cursos sobre América Latina y la potencia rusa. Finalmente, se concentró en estudiar a la región. Fruto de esa decisión, pidió en el verano de 1963 una beca para estudiar español en Harvard de forma sistemática. El período estival, además, lo aprovechó para asistir como oyente de un curso sobre América Latina de varias semanas, ofrecido en la Escuela de Verano de aquella casa de estudios, e impartido por Kalman Silvert. Allí el profesor y el alumno establecieron una relación de respeto y amistad, decisiva, sin duda, para la carrera profesional de Lowenthal.

DADOS - Revista de Ciências Sociais, Rio de Janeiro, vol. 60, nº 2, 2017 
La presencia de Silvert en Harvard es una buena muestra de cómo había profesores que hablaban y sentían interés sobre América Latina en las universidades norteamericanas más prestigiosas de principios de los años 1960. También, dado el contexto histórico, había una joven audiencia ávida de conocimiento y de información sobre la actualidad, lo que explicaría cómo estas nuevas generaciones fueron ocupando puestos estratégicos en diferentes instituciones y fueron estableciendo redes y contactos en la región según iban desarrollando su carrera profesional. Eso es justamente lo que le sucedió a Lowenthal al ser reclutado por Silvert, una vez terminados sus estudios, para trabajar en la Fundación Ford en 1964 en un programa de prácticas profesionales llamado "Trainnig associated". Desde ese año y hasta 1966 estuvo destinado a la República Dominicana como asistente de un proyecto social. Allí, y según su testimonio, Lowenthal aprendió muchísimo en cuanto a la actividad pública, la importancia de la comunicación y el establecimiento de redes ${ }^{21}$. Son hábitos y prácticas que le valieron para su posterior recorrido profesional. También durante ese período pasó algunas semanas en Jamaica y en Trinidad y Tobago para establecer contactos y relaciones para la Fundación Ford y para que él, a la vez, tuviera una visión más amplia del Caribe.

Su trayectoria es, sin duda, un buen ejemplo de ese ambiente proclive hacia lo "latinoamericano" que se iba generando dentro de la academia norteamericana. No solamente él se había interesado por América Latina durante su licenciatura, sino que, aparte de viajar a la República Dominicana, pudo a su vuelta iniciar cursos de doctorado en Harvard y perfilar el tema de sus tesis doctoral, dedicada a la intervención militar norteamericana en Santo Domingo. Además, en esa universidad tendría tiempo de coincidir con Gino Germani, a quien Lowenthal tuvo como miembro de jurado de un examen oral de ciencia política previo a escribir su tesis doctoral ${ }^{22}$. A mitad de sus estudios doctorales, sin embargo, Harry E. Wilhelm, jefe del Programa de América Latina y el Caribe de la Fundación Ford, le reclutó para trabajar nuevamente como funcionario de la institución.

De esta forma, entre julio de 1969 y junio de 1972, Lowenthal estuvo destinado a la oficina de Lima, donde fungió como Assistant Representative, Acting Representative y Advisor o Consejero del Programa de Ciencias Sociales de la Fundación Ford para la región. Entremedias de esa labor tuvo tiempo de terminar su tesis doctoral en Goverment y defenderla en Harvard en 1971. Aquellos tres años en Lima le dieron la 
posibilidad de escribir varios trabajos sobre Perú, y, sobre todo, le permitieron colaborar estrechamente con Kalman Silvert y con otros agentes e intermediarios de la Fundación Ford en América Latina como los ya nombrados Peter Bell, Jeffrey Puryear o Nita Manitzas. Después William Carmichael remplazaría a Wilhelm como responsable del Programa sobre América Latina de la Fundación Ford. Esa experiencia también le sirvió a Lowenthal para conocer profundamente el trabajo interno de la institución filantrópica, para aumentar su cartera de contactos con instituciones y académicos latinoamericanos, y para sensibilizarse de los problemas económicos, sociales y políticos de la región.

A su vuelta a Estados Unidos obtuvo una beca del Council on Foreign Relations para ampliar estudios posdoctorales en el Center for International Studies de la Universidad de Princeton. Allí permaneció entre septiembre de 1972 y junio de 1974, primero como Visiting Fellow y luego como Research Associate. Una vez más volvería a coincidir con Silvert y trabaría amistad con importantes estudiantes norteamericanos y latinoamericanos ${ }^{23}$. Al igual que en Princeton afianzó su amistad con Albert O. Hirschman, quien le ayudaría y le avalaría al poco tiempo con la iniciativa del Programa Latinoamericano del Wilson Center. Al terminar su beca, Lowenthal tuvo que decidir, sin embargo, entre regresar a la Fundación Ford, pues había recibido una oferta de trabajo de William Carmichael, o insertarse en la academia norteamericana. Se decantó por esta última opción y consiguió un trabajo como "Lecturer (part-time) in Public and International Affairs and Latin American Studies" en Princeton en septiembre de $1974^{24}$. Pudo así continuar en esa universidad y estar próximo a Silvert y a Hirschman. Compaginó hasta mitad de 1976 esa ocupación académica en Princeton, primero con un puesto de Asistente Director y luego con un cargo como Director de Estudios en el Council on Foreign Relations de Nueva York.

Además, Lowenthal participaría como consultor, entre junio de 1974 y diciembre de 1976, de las Comisiones Linowitz y Murphy convocadas para analizar las relaciones entre Estados Unidos y América Latina ${ }^{25}$. Aquellas experiencias fueron el parteaguas que le empujaron a proponer la formación de una comisión permanente en Washington que estudiase las relaciones interamericanas. Esta propuesta la incluyó originalmente en un ensayo escrito junto a Gregory Traberton en 1974, titulado "USLatin American Relations: The Conduct of Routine Relations", y que fue presentado al Congreso estadounidense. Muchas

DADOS - Revista de Ciências Sociais, Rio de Janeiro, vol. 60, nº 2, 2017 
ideas contenidas en ese documento de trabajo fueron mejoradas y matizadas por Lowenthal durante diciembre de 1975 y recogidas en su proyecto del Programa Latinoamericano del Wilson Center. Veamos, a continuación, la maduración de ese proyecto.

\section{EL PROGRAMA LATINOAMERICANO DEL WOODROW WILSON CENTER EN EL CONTEXTO DE CONSOLIDACIÓN DE LOS LATIN AMERICAN STUDIES EN ESTADOS UNIDOS}

Para trasladar su idea de estudios latinoamericanos a la realidad, Abraham F. Lowenthal se encontró, para su suerte, con un ambiente político mucho más abierto y favorable en los Estados Unidos y en el Washington de mitad de los años 1970, coincidente con el final de las Administraciones Nixon y Ford. Todavía en su puesto en el Council on Foreign Relations, decidió buscar soportes financieros y socios intelectuales, poniendo en juego todo su capital académico y social acumulado en forma de prestigio y de cartera de contactos y relaciones persona$l^{1} \mathrm{~s}^{26}$. De esta forma, acudió con su propuesta a Henry Owen, director de la División de Estudios de Política Exterior de la Brooklyn Institution, y a James Billington, director del Woodrow Wilson Center ${ }^{27}$. Fue este último quien más se interesó por su proyecto y quien le encargó la responsabilidad de prepararlo y dirigirlo en aquella institución a condición de que él mismo encontrase el correspondiente financiamiento. Gracias a su pasado en la Fundación Ford pudo conseguir a lo largo de 1976 las donaciones de esta entidad como el respaldo financiero también de la Fundación Rockefeller, la Rockefeller Brothers Fund y la Kettering Foundation (Lowenthal, 2014).

Una vez obtenidos los recursos económicos y los apoyos institucionales necesarios, Lowenthal fue terminando de perfilar el proyecto a finales de 1976. Se valió entonces del poder convocante de Hirschman para sumar voluntades y definir quiénes debían ocupar el primer Consejo Académico del Programa Latinoamericano (Adelman, 2013:575). Precisamente el profesor de origen alemán le recomendó a Cardoso y a O`Donnell. Lowenthal, de hecho, ya conocía a estos dos científicos latinoamericanos, como igualmente a Foxley, de sus años de agente de la Fundación Ford en la región. No dudó entonces en sumarlos al proyecto al igual que invitó a Hirschman a presidir la futura comitiva. Mientras, él concluyó el diseño del programa bajo unas ideas-fuerza muy claras: 
que fuera un programa con reputación y con una mirada crítica y abierta, con altos estándares académicos e intelectuales, y que expresase interés en los asuntos políticos y económicos contemporáneos, con un compromiso por los valores de los derechos humanos y del gobierno democrático para así comprometer en la construcción de este esfuerzo a los intelectuales latinoamericanos (Lowenthal, 2014).

En ese momento no se sabía que Jimmy Carter iba a ser elegido presidente de los Estados Unidos. Eso vendría poco después. Pero sí es cierto que el Programa Latinoamericano evocaba el espíritu de renovación que se vislumbraba en el interior de la política estadounidense ${ }^{28}$. También fue un momento de afianzamiento y de consolidación de los Latin American Studies en Estados Unidos con otras iniciativas parecidas que deben ser mencionadas, como la Washington Office on Latin America (WOLA) o el Council on Hemispheric Affairs (COHA). Hubo, en consecuencia, más cultura sociológica y política sobre América Latina, más manejo del idioma español, más traducciones al inglés, más boletines y nuevas revistas especializadas, como Latin American Perspectives, fundada en 1974. Además los temas de actualidad sobre la región eran discutidos ampliamente en revistas académicas de otras disciplinas, como Current Sociology, Foreign Policy, Foreign Affairs, o en revistas político-culturales radicales como NACLA Newsletter (North American Congress Latin America), Review of Radical Political Economics o Monthly Review (Chilcote, 2006; Doughty, 2006; Karl, 2006).

Parte de este interés creciente se debió asimismo a la capacidad que tuvo la teoría de la dependencia latinoamericana, en sus diferentes versiones y con sus distintos protagonistas, de circular, incrustarse y dialogar incluso críticamente con los Latin American Studies ${ }^{29}$. Formulada inicialmente por Fernando H. Cardoso y Enzo Faletto en su libro Dependencia y desarrollo en América Latina, de 1969, obra que proponía una síntesis entre la teoría marxista y la sociología comprensiva weberiana para explicar las causas del subdesarrollo regional, ésta tuvo repercusiones en Estados Unidos, aunque sin conseguir tocar los pilares y las jerarquías de aquel sistema académico. Pero sí es cierto que una pequeña parte de sus exponentes fueron capaces de introducirse en la academia norteamericana y de consagrarse individualmente $^{30}$.

El caso más evidente es el del mismo Cardoso, quien, como estamos viendo logró establecer sólidos y duraderos lazos con sus intelectuales

DADOS - Revista de Ciências Sociais, Rio de Janeiro, vol. 60, n² 2, 2017 
Juan Jesús Morales

e instituciones, como también consiguió que se debatiera en aquél país sobre el dependentismo latinoamericano. Precisamente uno de sus trabajos norteamericanos más discutidos fue "The Consumption of Dependency Theory in the United States", publicado en 1977 por Latin American Research Review ${ }^{31}$. Ese artículo, no en vano, era producto de una estancia en el Instituto de Estudios Avanzados de la Universidad de Princeton junto a Hirschman y había sido presentado originalmente en 1976 en el encuentro anual de la LASA. Lo más destacado de ese escrito, aparte de criticar el dependentismo distorsionado y simplificado que llegó a Estados Unidos de la mano de André Gunder Frank, es la renuncia del propio Cardoso a la tradición dependentista mal entendida (Cardoso, 1977:8-12). Su preocupación ya no estaba en las situaciones de dependencia en América Latina, sino en apuntar las posibilidades del retorno democrático. Este giro individual representa, a su vez, la eclosión de un movimiento colectivo en el campo académico latinoamericano de los estudios sobre el autoritarismo y sobre la democracia como una corriente intelectual de dimensión regional e internacional.

El Programa Latinoamericano del Wilson Center se nucleó, en consecuencia, alrededor de los derechos humanos y de la gobernanza democrática en América Latina, aparte de las relaciones internacionales y la política exterior norteamericana respecto a sus vecinos hemisféricos ${ }^{32}$. Y en esos temas fue importantísima la experiencia y la reflexión política de los académicos de la región sobre los regímenes "burocráticoautoritarios" y sus características, siendo ahí fundamentales los trabajos de Guillermo O'Donnell (Lowenthal, 1983:158) ${ }^{33}$. Por tal motivo, y como gran novedad y característica del Programa, se quiso que estas voces latinoamericanas participasen activamente en sus directrices y directivas junto con sus pares norteamericanos. Fue ese espíritu de diálogo interamericano el que caracterizó al primer Consejo Académico, presidido por Albert $\mathrm{O}$. Hirschman, con 5 de los 9 miembros provenientes de América Latina: a los ya nombrados Cardoso y O`Donnell, se sumaron Ricardo Ffench Davis, de CIEPLAN, Leslie Manigat, de la Universidad Simón Bolívar de Caracas, y Olga Pellicer de Brody, del CIDE mexicano (Lowenthal, 1998:12)

Esta representación latinoamericana en el Consejo Académico fue uno de los rasgos que le hacía diferente respecto a otros programas académicos y universitarios. Que apareciesen los nombres de Cardoso, O'Donnell o French Davis (estrecho colaborador de Foxley en CIEPLAN) evidencia el funcionamiento de las redes de intercambio in- 
teramericano y, en este caso particular, el importante canal de reclutamiento y de confianza que hiló la Fundación Ford entre las dos Américas, teniendo estrechas conexiones con las más prestigiosas universidades norteamericanas. Además, por supuesto, reflejan la trascendencia de los apoyos personales y las correspondencias intelectuales, como la perspectiva multidisciplinar que Lowenthal y Hirschman compartían. Pues, como así hicieron, pensaron que lo mejor era reclutar a estadounidenses y latinoamericanos de diferentes disciplinas, como la ciencia política, la historia, la sociología, las relaciones internacionales o la economía (Lowenthal, 2014). Ese matiz es el que, en definitiva, distingue a este programa de estudios latinoamericanos, inaugurado en febrero de 1977, y que desde entonces es reconocido como uno de los centros más prestigiosos de discusión y de investigación avanzada sobre América Latina, el Caribe y entre las Américas.

\section{CONCLUSIONES}

En las páginas anteriores hemos descrito el auge y la consolidación de los Latin American Studies en Estados Unidos como un proceso de intercambio y retroalimentación entre diferentes actores de la sociedad civil norteamericana, e sus universidades e instituciones privadas, y entre sus organismos públicos y sus tradiciones científicas. Pero también se destacaron las repercusiones que tuvieron para esa tarea los destinos históricos y políticos de América Latina junto con el auge, la consolidación y la internacionalización de sus ciencias sociales. Todo ello combinado, por supuesto, con los intereses geoestratégicos de Estados Unidos y la acción diplomática de sus fundaciones filantrópicas sobre la región. Estos antecedentes actuaron, sin duda alguna, como dispositivos institucionales, simbólicos e intelectuales que beneficiaron la implantación de disciplinas; crearon unas condiciones favorables para una mayor información y comunicación recíproca entre los científicos sociales de ambas Américas; alentaron la movilidad académica internacional; favorecieron la llegada a la academia norteamericana de una joven generación de científicos sociales latinoamericanos que, por diversos motivos, decidió quedarse (exilios, migraciones, mejores oportunidades laborales, etc.); $y$, al fin y al cabo, estas condiciones estructurales permitieron la emergencia de una nueva élite de productores de saberes culturales especializados (Lowenthal, 1983:155).

Nos detuvimos en los cruces asociativos, intelectuales y personales hilados por las redes del Programa para Latinoamérica de la Fundación

DADOS - Revista de Ciências Sociais, Rio de Janeiro, vol. 60, n’ 2, 2017 
Ford que convergieron, más otras variables contextuales y según las trayectorias biográficas estudiadas, en el caso del Programa Latinoamericano del Wilson Center. Pues la maduración de una idea de Abraham F. Lowenthal terminó por convertirse en una aspiración colectiva y compartida por un buen número de socios académicos. Ahí nos encargamos de destacar el papel convocante de Albert O. Hirschman y la presencia de científicos sociales latinoamericanos en su primer Consejo Académico, como Fernando H. Cardoso y Guillermo O'Donnell. Un hecho que responde al objetivo principal de este artículo a la hora de examinar el funcionamiento de estas redes interamericanas de cooperación académica establecidas por la Fundación Ford en la región. Como también nos sirvió para ver cómo se desplegaron y se pusieron en juego en esa actividad mancomunada del Wilson Center los capitales académicos, las credenciales intelectuales y los contactos adquiridos en esta red de ida y vuelta entre las dos Américas.

Pero, además, el estudio de esta trama tejida al alero de la Fundación Ford nos ayudó a saber cómo actúan los actores externos sobre las ciencias sociales latinoamericanas en aspectos relativos a la movilidad académica y a la circulación de ideas y transferencia de conocimiento entre el Norte y el Sur americanos. La política diplomática que siguió esta institución filantrópica durante la coyuntura de las dictaduras militares, fundamentada en apoyos informales y mutuos, permitió resguardar el desenvolvimiento de la reflexión sociológica y política a partir del sustento financiero de varios centros académicos independientes, como CEBRAP, CEDES o CIEPLAN, y ayudó tanto a difundir internacionalmente su conocimiento como a promocionar la carrera de algunos de sus investigadores.

De esta forma, el discurso académico y político de algunos autores latinoamericanos, especialmente Cardoso y O'Donnell, encontró apoyos en la academia norteamericana y en sus instituciones. Pues la red aquî estudiada estuvo fundamentada en afinidades intelectuales, personales y políticas sobre la democracia, más allá de las correspondientes diferencias y matices. En todo caso, este dato revela cómo el proceso de democratización de los años 1980 en América Latina tuvo un claro componente transnacional, interamericano e internacional. Pues ese fenómeno político logró una amplia conciencia entre sectores académicos y políticos regionales y generó una manifiesta simpatía entre sus pares norteamericanos y extranjeros ${ }^{35}$. 
A la vez, el análisis de estas interacciones interamericanas facilitadas y promovidas por la Fundación Ford nos permitió identificar los canales y mecanismos de consagración en Estados Unidos seguidos por estos autores latinoamericanos, siendo confiados y reconocidos incluso con credenciales de responsabilidad institucional en aquel país. Esto les permitiría encabezar después otras iniciativas, como sucedió con la creación del The Kellog for International Studies de la Universidad de Notre Dame en el año 1983, y cuyo primer director académico fue Guillermo O'Donnell, siendo ayudado también en esas tareas organizativas por Alejandro Foxley. Al igual que Fernando H. Cardoso y el propio Foxley serían convocados por Abraham F. Lowenthal en el Diálogo Interamericano, creado en 1982 en Washington como un think tank de intercambio entre académicos, líderes políticos y profesionales de las dos Américas ${ }^{36}$.

Son buenos ejemplos, en fin, de cómo esta élite consiguió generar en Estados Unidos espacios académicos especializados sobre los estudios latinoamericanos. Desde entonces es habitual que profesores y científicos sociales de la región disfruten de becas y de estancias de investigación en esas instituciones, consolidando y reproduciendo un modelo particular de circulación de las élites académicas latinoamericanas. También, por supuesto, este modelo actúa como canal de renovación y de reemplazo de estas minorías selectas en Estados Unidos.

(Recebido para publicação em junho de 2015)

(Reapresentado em junho de 2016)

(Aprovado para publicação em abril de 2017)

DADOS - Revista de Ciências Sociais, Rio de Janeiro, vol. 60, n’ 2, 2017 


\section{NOTAS}

1. Para el acopio de documentos y material bibliográfico sobre la Fundación Ford se contó con una beca del Archivo de la Fundación Rockefeller (RAC Grants Awards) para realizar una estancia en Nueva York durante septiembre de 2015. Además, para la extracción de información se realizó una entrevista en profundidad a Abraham F. Lowenthal el 24 de julio de 2014. También se hizo una lectura bibliográfica complementaria para esta investigación sobre el protagonismo de las fundaciones norteamericanas en la institucionalización de las ciencias sociales en Estados Unidos, en América Latina, como en otras partes del mundo, y sobre el papel de éstas como actores trasnacionales y sobre su función particular de unir academia y política (Ahmad, 1991; Faria y Conceição da Costa, 2006; Fisher, 1993; Grisendi, 2014; Miceli, 1993; Morcillo, 2016; Pereyra, 2004; Picó, 2001; Parmar, 2002). Por último, se recopiló material documental de CEBRAP, CEDES y CIEPLAN, los centros académicos latinoamericanos aquí seleccionados

2. El Joint Committee on Latin American Studies alentó y patrocinó importantes seminarios y encuentros entre científicos sociales interamericanos durante aquellos años y, sobre todo, ayudó a financiar en 1964 la formación de la Latin American Studies Asocciation (LASA) (Doughty, 2006). LASA viene publicando desde 1965 Latin American Research Review, una de las revistas más respetadas de esta disciplina.

3. La Revolución cubana actuó como uno de los motores más importantes para el desarrollo de los estudios latinoamericanos en la academia norteamericana, pues ésta quedó muy atenta a todo lo que sucedía en la región al considerarla como un activo laboratorio intelectual, social y político. Pero, además, desde el ámbito de la política se sintió una creciente preocupación y alarma por la proximidad geográfica de la amenaza comunista y marxista. América Latina quedó entonces incluida en el mapa de la Guerra Fría (Hirst y Russel, 2001). Aparte de las intervenciones militares, manifiestas y encubiertas, Estados Unidos apuntó al desarrollo socioeconómico y a la cooperación para desalentar las revoluciones sociales y asegurar así su hegemonía en América (Gabay, 2010; Quesada, 2012). Este cambio de postura política supuso un apoyo al establecimiento de regímenes civiles y democráticos con tal de detener los impulsos revolucionarios y la difusión del ejemplo cubano. Bajo esas circunstancias se entiende el ambicioso programa hemisférico de colaboración de la Alianza para el Progreso, propuesto por John F. Kennedy durante la campaña presidencial de 1960, anunciado a la Organización de Estados Americanos en marzo de 1961 y planteado a los presidentes latinoamericanos en la reunión de Punta del Este (Uruguay) en agosto de ese año.

4. Por ejemplo, el apoyo financiero de la Fundación Ford fue muy importante en la creación y el sostenimiento de investigaciones acometidas por parte del Instituto Latinoamericano de Planificación Económica y Social (ILPES), creado en Santiago de Chile en 1962 bajo la égida de la Comisión Económica para América Latina y el Caribe de las Naciones Unidas (CEPAL). Ver la Resolución NE 218 (AC.50) del 16 de febrero de 1962 de la CEPAL, "Sobre el Instituto Latinoamericano de Planificación Económica y Social (Santiago de Chile: Publicación del ILPES, 1962).

5. Este programa, diseñado para medir, predecir y controlar conflictos internos tendientes a la desestabilización social de países de la periferia, nació en la Special Operattions Office perteneciente a la American University, y fue contratado por el De- 
partamento de Defensa de Estados Unidos para ser aplicado en Chile. La denuncia del Camelot fue hecha por Johan Galtung, profesor noruego quien entonces desempeñaba labores de capacitación en la FLACSO de Santiago de Chile.

6. La Fundación Ford apoyó con sus donaciones la creación del Consejo Latinoamericano de Ciencias Sociales (CLACSO) en 1967 (Fundación Ford, 2003: 26). Este organismo regional nació igualmente motivado por las acciones del Joint Committee on Latin American Studies del SSRC, pues fueron los científicos sociales norteamericanos "quienes movilizaron a sus pares latinoamericanos para organizar una entidad regional" (Bayle, 2010: 239). De hecho, esta demanda colegial por parte de la academia norteamericana iba dirigida hacia el establecimiento de enérgicas vías de cooperación e intercambio académico, fuera a partir de proyectos conjuntos, seminarios o financiación de estancias de movilidad académica. Estas redes interamericanas actuarían también como redes de solidaridad cuando CLACSO puso en marcha un programa de reubicación dirigido a académicos latinoamericanos forzados al exilio por las dictaduras militares, contando también con el apoyo de la Fundación Ford (2003: 38). Añadir aquí que, junto a la clara inclinación estadounidense de los autores aquí estudiados, caso de Cardoso, Foxley y O`Donnell, también es pertinente señalar la vocación latinoamericana que trataron de impregnar a sus respectivos centros académicos. De esta forma, CEBRAP, CIEPLAN y CEDES fueron miembros activos de la red de CLACSO, acogiendo grupos de trabajo y ocupando sus investigadores puestos de responsabilidad en este organismo regional. De hecho, el propio Foxley fue durante varios años miembro del comité directivo de CLACSO. "Circulares CLACSO 1977-1980". CLACSO, Buenos Aires, 1980.

7. José Joaquín Brunner y Alicia Barrios (1987) generalizaron el uso del concepto "Centros Académicos Independientes" (CAI) para referirse a la aparición a nivel regional de nuevos organismos y de difusión de las ciencias sociales bajo el contexto autoritario en el Cono Sur, especialmente. Trabajos posteriores, como el de Víctor Algañaraz (2013), demuestran que en países como Argentina estos centros privados ya eran habituales en los años 50 del siglo XX.

8. Kalman Silvert había obtenido en 1947 la Penfield Fellowship para desarrollar en Chile una investigación sobre las industrias del país. En los años 1950 ejerció como profesor visitante de la Universidad de Buenos Aires. Además de agente de la Fundación Ford en América Latina, fue un gran promotor de la enseñanza e investigación de los estudios latinoamericanos en Estados Unidos. De hecho, fue el primer presidente de LASA (Adams, 2006; Quesada, 2010). Vemos, por tanto, en el caso de la trayectoria de Silvert estos cruces entre filantropía, diplomacia académica e interrelaciones académicas norteamericanas y latinoamericanas.

9. Rockefeller Archive Center (Nueva York). Ford Foundation records. Grant number 69-00644. Grant purpose “Support for Social Science Research at the Brazilian Center for Analysis and Planning (CEBRAP)".

10. Fernando H. Cardoso pertenecía a la "escuela sociológica" de la Universidad de São Paulo. Allí había trabajado con Florestan Fernandes y en 1961 se había doctorado con un estudio sobre "Capitalismo y esclavitud en el sur del Brasil", trabajo publicado en 1962.

11. "CEBRAP. Centro Brasileiro de Análise e Planejamento", Documento Institucional, s/f, p. 3.

DADOS - Revista de Ciências Sociais, Rio de Janeiro, vol. 60, n² 2, 2017 
Juan Jesús Morales

12. Rockefeller Archive Center (Nueva York). Ford Foundation records. Grant number 75-00550. Grant purpose "Partial support for CEDES' research and publications activities". Request No. ID-2357, 11 de agosto de 1975, p. 4.

13. “Reseña de Actividades”, CEDES, Buenos Aires, 1977, p. 1.

14. Guillermo O’Donnell se había licenciado en Derecho por la Universidad de Buenos Aires en 1957. En 1984 obtendría un doctorado en Ciencia Política por la Universidad de Yale.

15. Rockefeller Archive Center (Nueva York). Ford Foundation records. Grant number 76-00290. Grantee name "Corporation for Latin American Economic Research". Grant purpose "Support for research in Economic and Social Policy Issues". Request No. ID- 2976, 24 de julio de 1978, p. 4.

16. La Fundación Fullbright instauró en Chile en el año 1955 su primer programa de becas para América Latina (Navarro, 2013). Este hecho benefició la formación de numerosos estudiantes de la región, como también habilitó importantes redes de movilidad académica internacional. Esto se aprecia sucintamente en la trayectoria del propio Alejandro Foxley, quien había estudiado Ingeniería Civil Química en la Universidad Católica de Valparaíso entre 1957 y 1962, y que después de formarse en Estados Unidos entre 1963 y 1966 gracias a la beca Fulbright, entraría en este circuito académico internacional. Esto explicaría, por ejemplo, sus cargos posteriores como profesor en diversas universidades extranjeras, como en 1973, en el Institute of Development Studies de la Universidad de Sussex en Inglaterra, y en 1975, siendo docente en la Universidad de Oxford de ese mismo país.

17. Albert O. Hirschman recomendó a McGeorge Bundy, presidente de la Fundación Ford, las orientaciones optimistas y de apoyo a la democracia que debía seguir el Programa Latinoamericano de la institución filantrópica a pesar del complicado contexto (Adelman, 2011 y 2013). Él había formulado esa invitación a unir democracia y desarrollo socioeconómico en su ensayo A Bias for Hope: Essays on Development and Latin America, del año 1971.

18. Uno de los proyectos colaborativos más representativos de esa época fue, por ejemplo, el de "Políticas de "Normalización Económica" en los regímenes contemporáneos del Cono Sur de América Latina: Estudio de los casos de Argentina, Brasil, Chile y Uruguay", dirigido por Guillermo O’Donnell y codirigido por Alejandro Foxley, y que convocó a los investigadores de CEBRAP, CEDES y CIEPLAN entre 1977 y 1982. En la investigación también participaron algunos investigadores de los centros académicos uruguayos CINVE y CIESU, financiados igualmente por la Fundación Ford. Este proyecto se trató de un estudio sobre los aspectos políticos y económicos de los planes de normalización aplicados en esos países por las dictaduras militares (Algañaraz y Morales, 2016: 236). A los estudios nacionales se les sumó la confección de trabajos comparativos y en los que participaron el propio O’Donnell y Foxley, quien escribió informes para el proyecto como "Políticas de estabilización y sus efectos sobre el empleo y la distribución del ingreso. Una perspectiva latinoamericana", de 1979, o "Inflación con recesión. Las experiencias de Brasil y Chile", también de ese mismo año (CEDES, 1980:25-26 y 38). Además, Foxley publicó en 1982 el importante texto, corolario de la investigación, "Experimentos neoliberales en América Latina". El texto apareció originalmente en la Colección Estudios CIEPLAN y fue publicado después como libro en 1988 por el Fondo de Cultura Económica. 
19. Recordemos aquí que Albert O. Hirschman se desempeñó entre 1964 y 1974 como profesor en la Universidad de Harvard y luego desde 1974 hasta 1985 como Profesor de Ciencia Social en el Instituto de Estudios Avanzados de la Universidad de Princeton, y ya desde esa fecha hasta su fallecimiento en el año 2012 ejerció como profesor emérito de esa casa de estudios.

20. La Harvard Graduate School of Public Administration es la más prestigiosa Facultad norteamericana en la formación de funcionarios y profesionales de las políticas públicas y de la administración, como también sobresale por la capacitación y educación de líderes políticos. De hecho, funciona como una cantera de reclutamiento de personal cualificado para las agencias federales y gubernamentales de Estados Unidos. Fue fundada en 1936 y en 1966 pasaría a llamarse John F. Kennedy School of Governement (Dassin, 2004:8-9).

21. Entrevista mantenida por el autor con Abraham F. Lowenthal, 24 de julio de 2014.

22. La presencia de Gino Germani en Harvard ayuda a dar forma a la hipótesis de nuestra investigación de cómo hayamos profesores especialistas latinoamericanos en las más prestigiosas universidades norteamericanas. De hecho, cuando el sociólogo italo-argentino se incorporó a la Universidad de Harvard en 1966, algunos de sus compañeros ya tenían un amplio conocimiento del proceso desarrollista y modernizador contemporáneo de América Latina. Por ejemplo, Seymour Martin Lipset reconocía haber estado siempre bien interesado de las condiciones sociales y políticas de la democracia en la región (Lipset, 1996: 14). Además había publicado en español en 1965 un libro titulado, Estudiantes universitarios y política en el tercer Mundo. Al poco tiempo Lipset editaría junto con Aldo Solari el clásico Elites y desarrollo en América latina, publicado en 1967 y con versiones tanto en inglés como en español.

23. Lowenthal, además, coincidió en Princeton con Peter Winn, Shane Hunt, Richard Webb, Norman Gall, Paul Sigmund, Andrés Bianchi, Jorge G. Castañeda, Juan Gabriel Valdés o Carlos Caballero. En Princeton presidió el “Center's National Development Seminar", que invitaba al campus a importantes académicos para dar conferencias magistrales. Desde esa posición pudo conocer a otros nombres que en algún momento se implicaron y formaron parte del Programa Latinoamericano del Wilson Center, como Juan Linz o Philippe Schmitter (Lowenthal, 2014).

24. Si bien había rechazado la invitación de Carmichael, Lowenthal siempre contó con su apoyo y con el de la Fundación Ford para las iniciativas profesionales a las que se dedicó después. El fundamento de este respaldo se debía, sobre todo, al estilo paternalista y protector de trabajo y de ideario que caracterizó a la Fundación Ford de ese tiempo. Rasgo que explica, sin duda, cómo las redes institucionales o de cooperación académica en muchas ocasiones están sostenidas y fundamentadas en lazos y vínculos personales (entrevista mantenida por el autor con Abraham F. Lowenthal, 24 de julio de 2014).

25. La Comisión Linowitz fue establecida por el Center for Inter-American Relations de Nueva York, una organización no gubernamental presidida por David Rockefeller, quien la organizó en respuesta a una recomendación informal del Secretario de Estado Henry Kissinger. La Comisión Murphy, que es la comisión encargada de organizar la política exterior estadounidense, fue convocada conjuntamente por el Congreso y el Poder Ejecutivo, pero no se centró únicamente en las relaciones interamericanas (entrevista mantenida por el autor con Abraham F. Lowenthal, $24 \mathrm{de}$ julio de 2014).

DADOS - Revista de Ciências Sociais, Rio de Janeiro, vol. 60, nº 2, 2017 
26. En aquel entonces Lowenthal ya contaba con un par de libros de prestigio sobre América Latina, como The Dominican Intervention, de 1972, y The Peruvian Experiment: Continuity and Change Under Military Rule, de 1975. Además, tenía varios artículos publicados en revistas estadounidenses de impacto como Foreign Affairs, Foreign Policy o World Politics.

27. El Woodrow Wilson International Center for Scholars, con sede en Washington y en parte financiado con fondos públicos del gobierno norteamericano, fue creado en 1968 como un memorial dedicado a la figura del Presidente Woodrow Wilson, quien fue profesor de ciencia política y combinó la carrera académica con la vida política. Fue concebido como un centro internacional para el intercambio de ideas entre académicos, preferentemente científicos sociales y humanistas, y políticos de diferentes partes del mundo. Este nexo entre reflexión y acción es el que le distingue desde entonces como uno de los think tanks más importantes de Estados Unidos.

28. La posterior llegada de Carter a la presidencia norteamericana se sintió con un halo de esperanza en cuanto supusiera "una eventual apertura política en América Latina, auspiciada y promovida desde Estados Unidos" "Editorial", Cuadernos Semestrales, №1, abril 1977, p. 10). El relevo demócrata en Washington abría la posibilidad del cambio político en la región bajo la premisa de la "democracia viable" frente a las dictaduras militares imperantes. Y, obviamente, el Programa Latinoamericano del Wilson Center diseñado por Lowenthal es deudor de ese tiempo, de esas aspiraciones y de la nueva perspectiva norteamericana sobre la región. Entrevista mantenida por el autor con Abraham F. Lowenthal. 24 de julio de 2014.

29. En ese sentido destacan libros como el de Susanne J. Bodenheimer, The Ideology of Developmentalism: The American Paradigm-Surrogate for Latin American Studies, de 1971, el de Ronald Chilcote y Joel Edelstein, Latin America: The Struggle With Dependency and Beyond, del año 1974, o el de Joseph A. Kahl, Modernization, Exploitation, and Dependency in Latin America, de 1976.

30. Por ejemplo, Theotonio dos Santos publicó importantes trabajos en Estados Unidos, como su artículo "The Structure of Dependency" (American Economic Review, vol. 60, n을, 1970, pp. 231-36).

31. Este artículo también fue publicado en español como “El consumo de la teoría de la dependencia en Estados Unidos" (Trimestre Económico, vol. XLIV, nํ73, enero-marzo 1977).

32. Señalemos aquí la concordancia del Programa Latinoamericano del Wilson Center con los propósitos de la Fundación Ford respecto a América Latina, sobre todo a partir de los años 1980. Precisamente, Franklin A. Thomas, presidente de la Fundación Ford, señaló que esa década que recién comenzaba iba a ser decisiva para esta institución filantrópica estadounidense en cuanto se refiere a la promoción del estudio, análisis y "desarrollo" de la "gobernanza" y estabilidad democrática en el Tercer Mundo (Thomas, 1980:IX-X).

33. Pensemos que Cardoso en su artículo "The Consumption of Dependency Theory in the United States" cita un trabajo suyo dedicado sobre el tema, Autoritarismo e Democratização, de 1975. Y, además, comparte preocupaciones con Guillermo O'Donnell, refiriéndose al "perspicaz ensayo" de éste, Reflexiones sobre las tendencias generales de cambio en el Estado burocratico-autoritario, de 1975, publicado por el CEDES de Buenos Aires (Cardoso, 1977:24). Lowenthal, al igual que Cardoso, 
también sintió una afinidad intelectual con las investigaciones acometidas por O’Donnell alrededor de su concepto "Estado burocrático-autoritario", desarrollado originalmente por este autor en su libro Modernization and Bureaucratic Authoritarianism, de 1973.

34. Además figuraban los profesores Philippe Schmitter, de la Universidad de Chicago, Thomas Skidmore, de la Universidad de Wisconsin, y Karen Spalding, de la University de Delaware. A este Consejo Académico le competía reunirse anualmente durante dos días para evaluar los lineamientos del programa y seleccionar los becarios beneficiados, pues el Programa funciona, básicamente, becando a investigadores latinoamericanos, norteamericanos y europeos bajo el objetivo fundamental de que estos "fellows" contribuyan al diseño y al desarrollo de las políticas públicas y sociales en América Latina con sus investigaciones y con sus productos académicos. Los becarios disfrutan de una estancia de investigación de un semestre o un año en el mismo Wilson Center. Las becas, además, conceden todas las facilidades para la investigación sistemática, apoyo financiero internacional y pasantías en instituciones políticas, y en cuerpos gubernamentales de Washington. Entre las obligaciones de los becarios están la elaboración de informes, documentos de trabajo y la organización y participación en coloquios, workshops o conferencias sobre cuestiones relacionadas con sus áreas de interés y en relación a los estudios latinoamericanos en su conjunto (Lowenthal, 1982:203; Wilson Center, 1981:64-65).

35. Uno de los proyectos más destacados del Programa Latinoamericano del Wilson Center fue el de "Transitions from Authoritarian Rule to Democracy", comenzado en el año 1979 a partir de la iniciativa de Cardoso y O'Donnell y con el apoyo activo de Hirschman (Lowenthal, 1986:VIII). Cardoso abandonaría la coordinación del proyecto, dejándolo en manos de O'Donnell y de Philippe Schmitter, involucrado también desde sus inicios. En la medida que el proyecto fue creciendo en alcance y complejidad, y ya incluyendo los estudios sobre políticas comparadas y sobre las transiciones democráticas europeas, se sumaría Laurence Whitehead. Los diversos volúmenes publicados en 4 volúmenes por The Johns Hopkins University Press a partir del año 1986, tendrían hondo calado en el debate académico internacional al ser considerados como unos de los trabajos más influyentes en la historia de la política y de los estudios sobre democratización (Mainwaring, 2012:2).

36. Tras la salida de Lowenthal, el Programa Latinoamericano del Wilson Center tuvo sucesivos directores como Louis W. Goodman, Richard Morse, William Glade o Joseph Tulchin. Cardoso también abandonaría el Consejo Académico y su lugar sería ocupado en octubre de 1984 por Bolívar Lamounier, otro investigador de CEBRAP. 


\section{BIBLIOGRAFÍA}

ABARZÚA, Anabella. (2012), "Funcionarios Internacionales, sus Capitales, Disposiciones y Experticias: La Trayectoria de Horacio H. Godoy (1944-1978)". Sociedad Hoy, no 22 , pp. 61-75.

ADAMS, Richard N. (2006), "Some Personal Trivia about the Early Days". LASA Forum, vol. XXXVII, no 2, pp. 14-15.

ADELMAN, Jeremy. (2011), “Albert O. Hirschman's Early Institute Years”. Summer 2011 Issue, Institute for Advanced Study, Princeton University.

(2013), Worldly Philosopher: The Odyssey of Albert O. Hirschman. New Jersey, Princeton University Press.

ADELMAN, Jeremy; FAJARDO, Margarita. (2016), "Between Capitalism and Democracy. A Study in the Political Economy of Ideas in Latin America, 1968-1980". Latin American Research Review, vol. 51, no 3, pp. 3-22.

AHMAD, Salma. (1991), "American Foundations and the Development of the Social Sciences between the Wars: Comment on the Debate between Martin Bulmer and Donald Fisher". Sociology, no 25, pp. 511-520.

ALGAÑARAZ, Víctor. (2013), “Between Scientific Autonomy and Academic Dependency: Private Research Institutes Under Dictatorship in Argentina (1976-1983). The Case of FLACSO", en F. Beigel (ed.), The Politics of Academic Autonomy in Latin America. London, Ashgate, pp. 249-263.

_ _MORALES, Juan Jesús. (2016), “Ciencias Sociales, Políticas de Autonomía Académica y Estrategias de Internacionalización en la Última Dictadura Militar Argentina (1974-1983). Un Análisis de los Casos de la Facultad Latinoamericana de Ciencias Sociales y el Centro de Estudios de Estado y Sociedad". Revista Mexicana de Ciencias Políticas y Sociales, no 227, pp. 223-246.

ARNOVE, Robert (ed.). (1980), Philanthropy and Cultural Imperialism: The Foundations at Home and Abroad. Boston, G. K. Hall.

BAYLE, Paola. (2010), “La Migración Forzosa de una Población Calificada. El Programa de Reubicación de Cientistas Sociales, CLACSO y el Exilio Chileno (1973-1976)", en F. Beigel (dir.), Autonomía y Dependencia Académica. Universidad e Investigación Científica en un Circuito Periférico: Chile y Argentina (1950-1980). Buenos Aires, Editorial Biblos, pp. 233-269.

BEIGEL, Fernanda (dir.). (2010), Autonomía y Dependencia Académica. Universidad e Investigación Científica en un Circuito Periférico: Chile y Argentina (1950-1980). Buenos Aires, Editorial Biblos.

(ed.). (2013), The Politics of Academic Autonomy in Latin America. London, Ashgate.

BELL, Peter D. (1971), "The Ford Foundation as a Transnational Actor". International Organization, vol. 25, no 3, pp. 465-478.

BERGER, Mark T. (1995), Under Northern Eyes: Latin American Studies and U.S. Hegemony in the Americas, 1898-1990. Bloomington, Indiana University Press. 
BERMAN, Edward H. (1983), The Influence of the Carnegie, Ford, and Rockefeller Foundations on American Foreign Policy: The Ideology of Philanthropy. Albany, State University of New York Press.

BRUNNER, José Joaquín; BARRIOS, Alicia. (1987), Inquisición, Mercado y Filantropía. Ciencias Sociales y Autoritarismo en Argentina, Brasil, Chile y Uruguay. Santiago de Chile, FLACSO.

CALANDRA, Benedetta. (2011), “La Ford Foundation y la Guerra Fría Cultural”. Americanía, no 1, pp. 8-25.

. (2012), “Del “Terremoto” Cubano al Golpe Chileno: Políticas Culturales de la Fundación Ford en América Latina (1959-1973)", en B. Calandra; M. Franco (eds.), La Guerra Fría Cultural en América Latina. Desafíos y Límites para una Nueva Mirada de las Relaciones Interamericanas. Buenos Aires, Editorial Biblos, pp. 133-149.

. (2015), “De la Selva Brasileña a la Capital de las Ciencias Sociales: Proyectos Modernizadores de la Fundación Ford en América Latina, 1927-1965". Historia y Política, no 34, pp. 53-80.

CARDOSO, Fernando H. (1977), "The Consumption of Dependency Theory in the United States". Latin American Research Review, vol. 12, no 3, pp. 7-24.

. (2009), "Fernando Henrique Cardoso", en F. Moura; P. Montero (orgs.), Retrato de Grupo. 40 Anos do CEBRAP. São Paulo, Cosac Naify, pp. 18-49 (entrevistado por Fernando Limongi, André Singer, Flávio Moura y Henri Gervaiseau).

CEDES. (1980), “Reseña de Actividades. Enero 1979-Junio 1980”. Buenos Aires, CEDES.

CHILCOTE, Ronald H. (2006), “The Legacy of the Sixties and its Impact on Academics". LASA Forum, vol. XXXVII, no 2, pp. 22-24.

DASSIN, Joan. (2004), "Public Policy Training Programs in the United States: Characteristics and Linkages to Latin America", en J. Dassin; J. Tulchin; A. Brown (eds.), Training a New Generation of Leaders. Washington, Latin American Program, Woodrow Wilson International Center for Scholars, pp. 1-54.

DEVÉS, Eduardo. (2007), Redes Intelectuales en América Latina. Hacia la Constitución de una Comunidad Intelectual. Santiago de Chile, Instituto de Estudios Avanzados, Universidad de Santiago de Chile.

DEZALAY, Yves; GARTH, Bryant G. (2002), The Internationalization of Palace Wars: Lawyers, Economists, and the Contest to Transform Latin American States. Chicago, University of Chicago Press.

DOUGHTY, Paul. (2006), "Words from the Eighth President of LASA". LASA Forum, vol. XXXVII, no 2, pp. 16-18.

FARIA, Lina; CONCEIÇÃO, Maria. (2006), “Cooperação Científica Internacional: Estilos de Atuação da Fundação Rockefeller e da Fundação Ford". DADOS - Revista de Ciências Sociais, vol. 49, no 1, pp. 159-191.

FISHER, Donald. (1993), Fundamental Development of the Social Sciences: Rockefeller Philanthropy and the United States Social Research Council. Michigan, University of Michigan Press.

DADOS - Revista de Ciências Sociais, Rio de Janeiro, vol. 60, n² 2, 2017 
FORD FOUNDATION. (1960), The Ford Foundation Annual Report. Nueva York, Fundación Ford.

FOXLEY, Alejandro. (2013), “A Tribute to Albert O. Hirschman”. Inter-American Dialogue. Recurso electrónico disponible en http:/ / www.thedialogue.org/page.cfm?pageID $=32 \&$ pubID $=3309$.

FUNDACIÓN FORD. (2003), Fundación Ford: 40 Años en la Región Andina y en el Cono Sur. Santiago de Chile, Fundación Ford.

GABAY, Eliana. (2010), “El Fantasma de Raúl Prebisch (1963-1969) y el Surgimiento del Debate Dependentista en el ILPES”, en D. Pereyra (comp.), Historia de las Ciencias Sociales Latinoamericanas. San José, FLACSO Costa Rica, pp. 73-97.

_ ; MORALES, Juan Jesús; NAVARRO, Juan José. (2013), “La Alianza para el Progreso y el Instituto Latinoamericano de Planificación Económica y Social (ILPES)", en A. Bloch; M. R. Rodríguez (coords.), La Guerra Fría: América Latina y América del Norte, 1945-1970. Morelia, Universidad de Colima y Universidad Michoacana de San Nicolás de Hidalgo, pp. 287-303.

GONZÁLEZ-CHIARAMONTE, Claudio. (2008), “Expandiendo Paradigmas, Rediseñando Fronteras: La Diplomacia Cultural Norteamericana y la Construcción de una Comunidad Interamericana de Académicos". Revista Esboços, no 20, pp. 223-244.

GRISENDI, Ezequiel. (2014), “El Centro de la Periferia: Internacionalización de las Ciencias Sociales y Redes Académicas Latinoamericanas. Manuel Diegues Junior y los Avatares de la Sociología del Desarrollo". Crítica e Sociedade. Revista de Cultura Política, vol. 4, no 2, pp. 148-167.

HIRST, Mónica; RUSELL, Roberto. (2001), El Mercosur y los Cambios en el Sistema Político Internacional. Buenos Aires, Fundación OSDE.

KARL, Terry. (2006), "Comments on the Presentations about LASA in the 1960s". LASA Forum, vol. XXXVII, no 2, p. 25.

LIPSET, Seymour Martin. (1996), "Steady Work: An Academic Memoir". Annual Review of Sociology, vol. 22, pp. 1-27.

LOWENTHAL, Abraham F. (1982), "Latin American Program Woodrow Wilson International Center for Scholars". Latin American Research Review, vol. 17, no 3, pp. 202-206.

. (1983), "Research in Latin America and the Caribbean on International Relations and Foreign Policy: Some Impressions". Latin American Research Review, vol. 18, no 1, pp. 154-174.

. (1986), "Forewords", en G. O’Donnell; P. Schmitter (eds.), Transitions from Authoritarian Rule. Tentative Conclusions about Uncertain Democracies. Vol. 4. Baltimore, The Johns Hopkins University Press, pp. VII-X.

. (1998), “Reflections”, en The Latin American Program. 20 Years of Weaving People, Policies and Perspectives. Washington, Latin American Program, Woodrow Wilson International Center for Scholars, pp. 11-13.

. (2014), "The Wilson Center's Latin American Program". Documento de trabajo inédito. 
MAINWARING, Scott. (2012), "A Tribute to Guillermo O'Donnell”. LASA Forum, vol. XLIII, no 2, pp. 2-3.

MELLER, Patricio; WALKER, Ignacio. (2007), CIEPLAN: Thirty Years in Pursuit of Democracy and Development in Latin America. Ponencia preparada para el "Workshop Ownership in Practice", Paris, Francia.

MICELI, Sergio (org.). (1993), A Fundação Ford no Brasil. São Paulo, Sumaré/Fapesp.

MORALES, Juan Jesús. (2012), “De los Aspectos Sociales del Desarrollo Económico a la Teoría de la Dependencia. Sobre la Gestación de un Pensamiento Social Propio en Latinoamérica". Cinta de Moebio, no 45, pp. 235-252.

. (2016a), “Un Circuito Latinoamericano de Centros Académicos Independientes alrededor de la Fundación Ford: Circulación del Conocimiento, Cooperación Científica y Financiación Filantrópica en Tiempos de Autoritarismo", en M. Hamuy; R. Ramírez (coords.), Perspectivas sobre Internacionalización en Educación Superior y Ciencia. México, DF., Cinvestav, Rimac, pp. 131-159.

. (2016b), “Entre la Ciencia y la Política: La Forja de una Élite Intelectual Latinoamericana". Política / Revista de Ciencia Política, vol. 54, no 1, pp. 157-188.

MORCILLO, Álvaro. (2016), “La Dominación Filantrópica. La Rockefeller Foundation y las Ciencias Sociales en Español (1938-1973)”, en Á. Morcillo Laiz; E. Weisz (eds.), Max Weber: Una Mirada Iberoamericana. México, DF., Fondo de Cultura Económica, pp. 573-605.

MORSE, Richard M. (1977), “Kalman H. Silvert (1921-1976): A Reminiscence”. The Hispanic American Historical Review, vol. 57, no 3, pp. 504-510.

NAVARRO, Juan José. (2013), “Public Foreign aid and Academic Mobility. The Fulbright Programme (1955-1973)", en F. Beigel (ed.), The Politics of Academic Autonomy in Latin America. London, Ashgate, pp. 102-118.

NAVARRO, Juan José; QUESADA, Fernando. (2010), “El Impacto del Proyecto Camelot en el Período de Consolidación de las Ciencias Sociales Latinoamericanas", en D. Pereyra (comp.), Historia de las Ciencias Sociales Latinoamericanas. San José, FLACSO Costa Rica, pp. 55-71.

O'DONNELL, Guillermo. (2007), “Democratization, Political Engagement, and Agenda- Setting Research", en G. L. Munck; R. Snyder (eds.), Passion, Craft, and Method in Comparative Politics. Baltimore, The Johns Hopkins University Press, pp. 273-304.

PARMAR, Inderjeet. (2002), "American Foundations and the Development of International Knowledge Networks". Global Networks, vol. 2, no 1, pp. 13-30.

PEREYRA, Diego E. (2004). American Organizations and the Development of Sociology and Social Research in Argentina. The Case of the SSRC and the Rockefeller Foundation (1927-1966). New York, Rockefeller Archive Center.

PICÓ, Josep. (2001), “El Protagonismo de las Fundaciones Americanas en la Institucionalización de la Sociología (1945-1960)”. Papers, nos 63/64, pp. 11-32.

PURYEAR, Jeffrey. (1994), Thinking Politics, Intellectuals and Democracy in Chile, 1973-1988. Baltimore, The Johns Hopkins University Press.

DADOS - Revista de Ciências Sociais, Rio de Janeiro, vol. 60, n² 2, 2017 


\section{Juan Jesús Morales}

QUESADA, Fernando. (2010), "La Marea del Pacífico. La Fundación Ford en Chile (1963-1973)", en F. Beigel (dir.), Autonomía y Dependencia Académica. Universidad e Investigación Científica en un Circuito Periférico: Chile y Argentina (1950-1980). Buenos Aires, Editorial Biblos, pp. 89-101.

. (2012), “Un Modelo para el Desarrollo: La Cooperación entre Chile y California y el Papel del Financiamiento Público y Privado Norteamericano". Estudios Avanzados, no 18, pp. 11-34.

. (2015), La Universidad Desconocida. El Convenio Universidad de Chile-Universidad de California y la Fundación Ford. Mendoza, Universidad Nacional de Cuyo.

RIZZO, Natalia. (2012), “Los Profesionales de Estado en Argentina: El Caso del Instituto del Servicio Exterior de la Nación (ISEN)". Cuadernos de Política Exterior Argentina, no 107, pp. 1-22.

SIBLEY, Elbridge. (2001), "Social Science Research Council: The First Fifty Years”, en K. W. Worcester (ed.), Social Science Research Council, 1923-1998. New York, Social Science Research Council, pp. 154-223. Trabajo original de 1974.

THOMAS, Franklin. (1980), “The President's Review”, en 1980 Annual Report. New York, Ford Foundation, pp. V-XI.

WILSON CENTER. (1981), “Fellowships: Woodrow Wilson International Center for Scholars". Science, Technology, \& Human Values, vol. 6, no 36, pp. 64-65.

WORCESTER, Kenton W. (2001), “Social Science Research Council, 1923-1998”, en K. W. Worcester (ed.), Social Science Research Council, 1923-1998. New York, Social Science Research Council, pp. 11-150. 


\section{RESUMO}

Cientistas Sociais Latino-americanos nos Estados Unidos: Cooperação Acadêmica, Mobilidade Internacional e Trajetórias Interamericanas em torno da Fundação Ford

O principal objetivo deste artigo consiste em examinar as redes de cooperação acadêmica e os canais de mobilidade internacional estabelecidos pela Fundação Ford na América Latina, os quais intervieram como plataformas para a promoção, em terras estadunidenses, de cientistas sociais da região. O interesse reside em compreender as interações e vínculos de vários autores latino-americanos com alguns "diplomatas" desta instituição filantrópica, no intuito de desenvolverem atividades institucionais e intelectuais nos Estados Unidos. Especificamente, serão analisadas as origens do Programa LatinoAmericano do Woodrow Wilson International Center for Scholars, fundado em Washington no ano de 1977, em decorrência de intervenções e mediações pessoais de Abraham F. Lowenthal. Além disso, e seguindo um enfoque histórico, acompanharemos temporal e espacialmente a trajetória deste autor e os seus laços intelectuais e pessoais estabelecidos com Fernando Henrique Cardoso, Albert O. Hirschman, Guillermo O’Donnell e Kalman Silvert.

Palavras-chave: cientistas sociais latino-americanos; Fundação Ford; cooperação acadêmica; mobilidade internacional; Latin American Studies

\section{ABSTRACT \\ Latin American Social Scientists in the United States: The Ford \\ Foundation's Role in Academic Cooperation, International Mobility, and Inter-American Trajectories}

This article's main objective is to examine the academic cooperation networks and international mobility channels established by the Ford Foundation in Latin America, to have served as platforms for showcasing social scientists from the region in the United States. Our interest is in understanding how the interactions and links between various Latin American authors and several "diplomats" from this charitable institution were fostered in order to develop institutional and intellectual activities in the United States. The article places a particular focus on studying the origins of the Latin American Program at the Woodrow Wilson International Center for Scholars, established in Washington in 1977 by means of Abraham F. Lowenthal's personal efforts to manage and mediate. A historical focus is also employed to temporally and spatially analyze the author's career path and his intellectual and personal ties developed with Fernando H. Cardoso, Albert O. Hirschman, Guillermo O’Donnell, and Kalman Silvert.

Keywords: Latin American social scientists; Ford Foundation; academic cooperation; international mobility; Latin American Studies

DADOS - Revista de Ciências Sociais, Rio de Janeiro, vol. 60, n² 2, 2017 
Juan Jesús Morales

\section{RÉSUMÉ}

Sociologues Latino-américains aux États-Unis: Le Rôle de la Fondation Ford dans la Coopération Académique, la Mobilité Internationale et les Trajectoires Interaméricaines

Le principal objectif de cet article est d'analyser les réseaux de coopération académique et de mobilité internationale établis par la Fondation Ford en Amérique Latine et qui ont servi de plate-forme de promotion de sociologues de la région aux États-Unis. Il s'agit ici de comprendre comment les interactions et les liens entre différents auteurs latino-américains et certains "diplomates" de cette institution philanthropique ont permis de développer leurs activités institutionnelles et intellectuelles aux États-Unis. Nous étudierons en particulier les origines du Programme latino-américain du Woodrow Wilson International Center for Scholars, lancé à Washington en 1977 grâce aux actions et médiations d'Abraham F. Lowenthal. En outre, dans une perspective historique, nous analyserons la trajectoire temporelle et spatiale de cet auteur et ses liens intellectuels et personnels avec Fernando H. Cardoso, Albert O. Hirschman, Guillermo O’Donnell et Kalman Silvert.

Mots-clés: sociologues latino-américains; Fondation Ford; coopération académique; mobilité internationale; Latin American Studies

\section{RESUMEN}

Científicos Sociales Latinoamericanos en Estados Unidos: Cooperación

Académica, Movilidad Internacional y Trayectorias Interamericanas alrededor de la Fundación Ford

El objetivo principal de este artículo es examinar las redes de cooperación académica y los canales de movilidad internacional establecidos por la Fundación Ford en América Latina, los cuales actuaron como plataformas de promoción de científicos sociales de la región en Estados Unidos. El interés está puesto en comprender las interacciones y los vínculos entre varios autores latinoamericanos con algunos "diplomáticos" de esta institución filantrópica para desarrollar en ese país actividades institucionales e intelectuales. De forma específica, se estudiarán los orígenes del Programa Latinoamericano del Woodrow Wilson International Center for Scholars, establecido en Washington en 1977 por las gestiones y mediaciones personales de Abraham F. Lowenthal. Además, y siguiendo un enfoque histórico, se hará un seguimiento temporal y espacial a la trayectoria de este autor y a sus nexos intelectuales y personales mantenidos con Fernando H. Cardoso, Albert O. Hirschman, Guillermo O'Donnell y Kalman Silvert.

Palabras clave: científicos sociales latinoamericanos; Fundación Ford; cooperación académica; movilidad internacional; Latin American Studies 